\title{
System dynamics modeling of childhood obesity
}

Behrouz Madahian ${ }^{1}$, Robert C Klesges ${ }^{2}$, Lisa Klesges ${ }^{3}$, Ramin Homayouni ${ }^{1,4^{*}}$

From 11th Annual UT-ORNL-KBRIN Bioinformatics Summit 2012

Louisville, KY, USA. 30 March - 1 April 2012

\section{Background}

Effective strategies for prevention of obesity have been elusive since the recognition of obesity as a major public health issue [1]. Obesity is a result of chronic, quantitative imbalance between energy intake and energy expenditure, influenced by a combination of genetic, environmental, psychological and social factors. Therefore, a systems perspective is needed to examine effective obesity prevention strategies [2]. In this study, a system dynamics model was developed using the data from the Girls health Enrichment

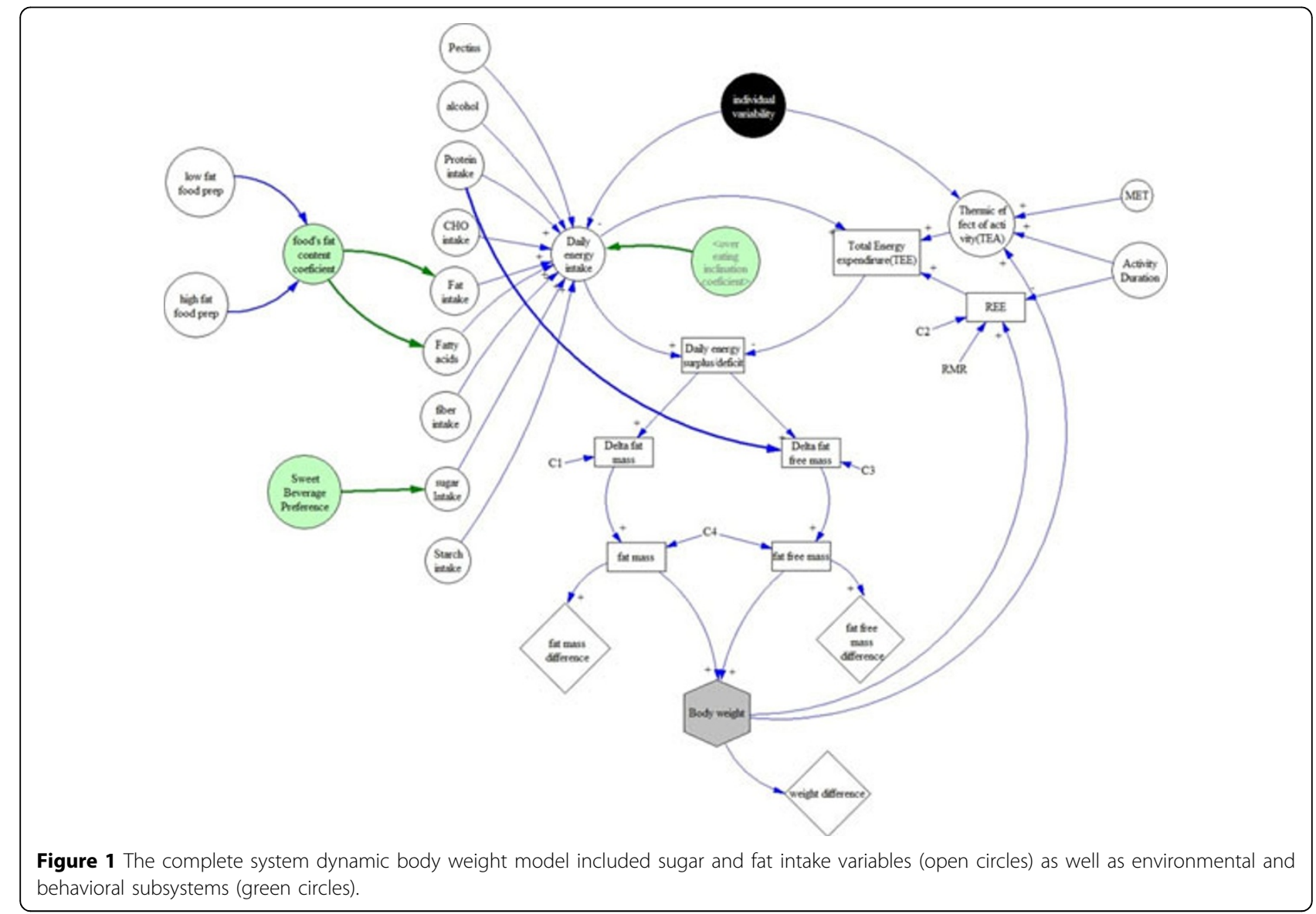

* Correspondence: rhomayon@memphis.edu

${ }^{1}$ Bioinformatics Program, University of Memphis, Memphis, TN 38152, USA

Full list of author information is available at the end of the article 
Multi-site Studies (GEMS). GEMS tested the efficacy of a 2-year family-based intervention to reduce excessive increase in body mass index in 8-10 year old AfricanAmerican girls.

\section{Methods}

System dynamics models were built using Vensim software (Ventana Systems, Inc) [3]. First, a core model was built which contained energy intake, energy expenditure and energy surplus subsystems contributing to the total body weight $[4,5]$. Then, an optimum model was built by systematically adding variables (from among 313 collected in GEMS) to fit the observed data by regression analysis for 50 randomly selected individuals from the cohort. The final model included nutrition, physical activity, and several environmental and behavioral factors (Figure 1).

\section{Results and discussion}

We evaluated the performance of a large number of models containing different food intake, energy expenditure and environmental variables collected in GEMS. The BMI simulated by our final complete model showed a correlation coefficient of 0.83 with the observed data, whereas the initial core model showed a correlation of 0.55 . The model accuracy was within $10 \%$ for $84 \%$ of the individuals in the study. For a few individuals, the simulated BMI and observed BMI values were greatly (>35\%) different. It is possible that the data collected from these individuals were inaccurate or, alternatively, it is possible that these individuals had other confounding factors (e.g. genetic variability) that were not captured in the study. Consistent

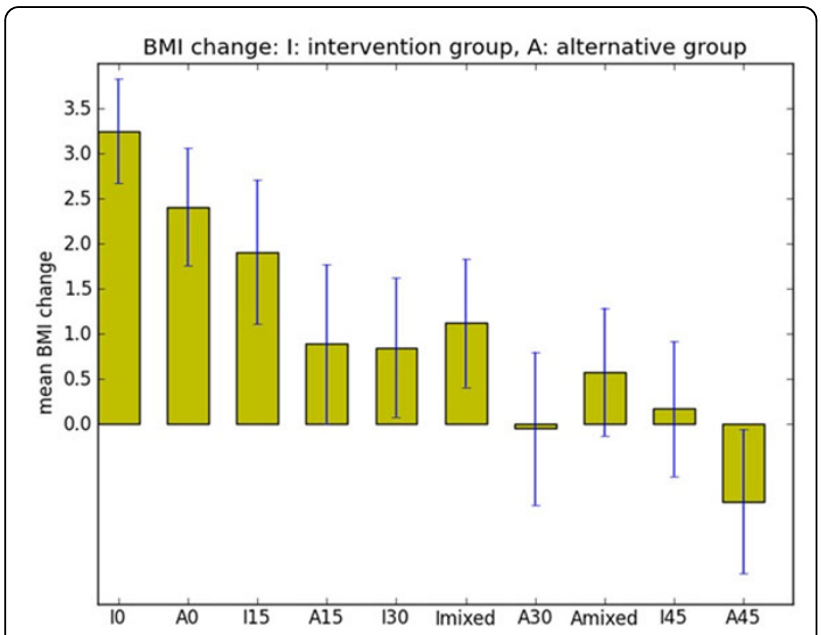

Figure 2 Comparison of various intervention schemes on simulated $\mathrm{BMI}$ change. The GEMS cohort consists of an intervention group (I) and an alternative group (A). Different durations (0, 15, 30 and 45 $\mathrm{min}$ ) of exercise were simulated for both groups as denoted on the $x$-axis. In addition, a 'mixed' intervention was simulated which included $10 \mathrm{~min}$ of exercise with a $100 \mathrm{cal}$ reduction in food intake. with previous observations, we found that the two intervention strategies in the GEMS study did not affect the BMI increases observed in the cohort [1]. Interestingly however, using our model, we were able to compare various intervention strategies and found that 10 min exercise plus a reduction of intake by 100 calories produced the same effect on BMI change as 30 min of exercise per day (Figure 2). Our work suggests that system dynamics modeling may be useful for testing potential intervention strategies in complex disorders such as obesity.

\section{Acknowledgements}

The GEMS study was supported by cooperative agreements HL62662 and HL62663 from the National Heart, Lung, and Blood Institute, National Institutes of Health. This work was supported in part by The University of Memphis Bioinformatics Program, The University of Memphis School of Public Health, and the Memphis Research Consortium.

\section{Author details}

${ }^{1}$ Bioinformatics Program, University of Memphis, Memphis, TN 38152, USA. ${ }^{2}$ Department of Preventive Medicine, University of Tennessee Health Science Center, Memphis, TN 38163, USA. ${ }^{3}$ Department of Epidemiology and Social and Behavioral Sciences, University of Memphis, Memphis, TN 38152, USA. ${ }^{4}$ Department of Biology, University of Memphis, Memphis, TN 38152, USA.

Published: 31 July 2012

\section{References}

1. Klesges RC, Obarzanek E, Kumanyika S, Murray DM, Klesges LM, Relyea GE, Stockton MB, Lanctot JQ, Beech BM, McClanahan BS, Sherrill-Mittleman D, Slawson DL: The Memphis Girls' health Enrichment Multi-site Studies (GEMS): an evaluation of the efficacy of a 2-year obesity prevention program in African American girls. Arch Pediatr Adolesc Med 2010, 164(11):1007-1114.

2. Huang TT, Drewnowski A, Kumanyika SK, Glass TA: A systems-oriented multilevel framework for addressing obesity in the 21st century. Prev Chronic Dis 2009, 6(3):A82.

3. Eberlein RL, Peterson DW: Understanding models with Vensim(TM). European Journal of Operational Research, Elsevier 1992, 59(1):216-219.

4. Hammond RA: Complex systems modeling for obesity research. Prev Chronic Dis 2009, 6(3):A97.

5. Abdel-hamid T: Modeling the dynamics of human energy regulation and its implications for obesity treatment. System Dynamics Rev 2002, 18:431-471.

doi:10.1186/1471-2105-13-S12-A13

Cite this article as: Madahian et al:: System dynamics modeling of childhood obesity. BMC Bioinformatics 2012 13(Suppl 12):A13.

\section{Submit your next manuscript to BioMed Central and take full advantage of:}

- Convenient online submission

- Thorough peer review

- No space constraints or color figure charges

- Immediate publication on acceptance

- Inclusion in PubMed, CAS, Scopus and Google Scholar

- Research which is freely available for redistribution 